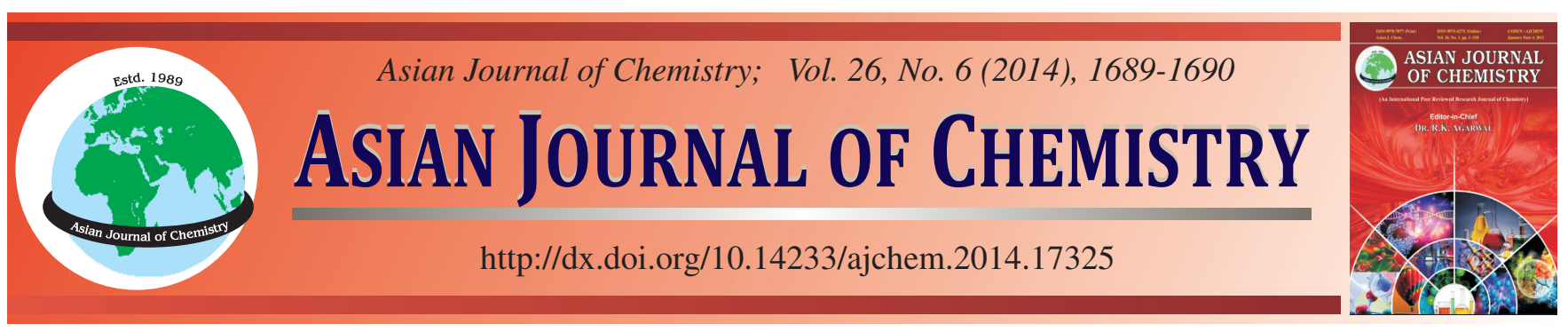

\title{
Adsorption Desulfurization on Azoles Modified ZSM5 Zeolite: A Theoretical Study $\dagger$
}

\author{
Hui Zhang ${ }^{1}$, Lijuan Hong ${ }^{1}$, JunXian $\mathrm{Chen}^{2}$, Fang $\mathrm{MeI}^{3}, \mathrm{Jun}^{3}{ }^{3}$ and Chan Kyung $\mathrm{Kim}^{3}, *$
}

${ }^{1}$ Department of Chemical and Materials Engineering, Hefei University, Hefei 230022, P.R. China

${ }^{2}$ College of Chemistry and Environment, Southwest University for Nationalities, Chengdu 610041, P.R. China

${ }^{3}$ Department of Chemistry, Inha University, 253 Yonghyun-dong, Nam-ku, Incheon 402-751, Republic of Korea

*Corresponding author: E-mail: kckyung@inha.ac.kr

Published online: 10 March 2014;

AJC-14866

The behaviour of sulfur dioxide adsorbed in imidazole modified ZSM5 zeolite has been investigated theoretically. The structures of
imidazole, triazole, tetrazole and part of compound are optimized by density functional theory B3LYP method in 6-31+G* basis set level.
The results show that zeolite ZSM5 present a better adsorption capability to sulfur dioxide after the molecules of azoles are inserted into
the zeolite sodalite cage, the adsorption capability is decreasing after the modified molecule is changed from imidazole to tetrazole.
Keywords: Azoles modified, ZSM5 zeolite, Desulfurization.

\section{INTRODUCTION}

Sulphur dioxide $\left(\mathrm{SO}_{2}\right)$ is an important atmospheric pollutant which causes many problems such as the plant corrosion, the respiratory disease and the acid rain ${ }^{1}$.

Adsorption desulfurization is a new and highly efficient method to remove $\mathrm{SO}_{2}$ from industrial gas and transportation fuels ${ }^{2}$. Recently, nanosized zeolite crystals have been attracting wide attention in the catalysis community and are becoming a potential desulfurization sorbent. Compared with micro size zeolite crystals, nano size materials such as zeolite exhibit a higher activity, a lower coke content and a longer life as catalysts in many reactions ${ }^{3}$. Various techniques are being explored for the synthesis of nano size zeolites and some researchers report that the ability of zeolite to capture $\mathrm{SO}_{2}$ is not so strong ${ }^{4}$.

Ionic liquids (ILs) have been widely used in the field of acid gas separation for gases such as $\mathrm{CO}_{2}, \mathrm{SO}_{2}, \mathrm{BF}_{3}$, etc. ${ }^{5}$. Recently, azole-based ionic liquids are attracted considerable attention because of their unique $\mathrm{SO}_{2}$ capture capability through multiple-site adsorption. Spectroscopic investigations and quantum-mechanical calculations show that such high $\mathrm{SO}_{2}$ capacity originates from the multiple sites of interaction between the azoles anion and $\mathrm{SO}_{2}$. These tunable azole-based ionic liquids with multiple sites offer significant improvements over commonly used absorbents, indicating the promise for industrial applications in acid gas separation ${ }^{6}$. As a new applicant in desulfurization field, azole-based ionic liquids achieve a high capacity as well as reversibility in the capture of gases such as $\mathrm{SO}_{2}$ at room temperature $\left(20^{\circ} \mathrm{C}\right)$, considering the high temperature $\left(200-300^{\circ} \mathrm{C}\right)$ at industrial desulfurization process, it is necessary to find a new material which can be combined with the advantages of zeolite and azole-based ionic liquids.

In this study, imidazole, triazole and tetrazole molecules are introduced into the sodalite cage of ZSM5 zeolite for getting a stable $\mathrm{SO}_{2}$ capture capability, so as to meet the requirements of industry application for this adsorption.

\section{EXPERIMENTAL}

The theoretical method and data set considered in this work is the same as that in earlier work ${ }^{7}$. The geometric structures of imidazole, triazole and tetrazole sulfur dioxide, fragment of ZSM5 zeolite and the compounds of ZSM5imidazole- $\mathrm{SO}_{2}, \mathrm{ZSM} 5$-triazole- $\mathrm{SO}_{2}$ and ZSM5-tetrazole- $\mathrm{SO}_{2}$ are fully optimized and characterized by frequency calculations by using the Gaussian 03 package ${ }^{8}$. All calculations are carried out by using Density Functional Theory (DFT) of B3LYP at $6-31+\mathrm{G}^{*}$ level and verified as minima having all positive force constants by frequency calculations. The optimized structures corresponded to global minima or at least local minimum in the potential energy surface.

†Presented at The 7th International Conference on Multi-functional Materials and Applications, held on 22-24 November 2013, Anhui University of Science \& Technology, Huainan, Anhui Province, P.R. China 


\section{RESULTS AND DISCUSSION}

In the present calculation, the ZSM5 zeolite is used, in which zeolite has a composition of a united cell in $\mathrm{Na}_{48} \mathrm{Al}_{48} \mathrm{Si}_{96} \mathrm{O}_{192}$, considering the calculation ability of our facility, ZSM5 zeolite is cut and an active part is kept, where the azoles and $\mathrm{SO}_{2}$ interact with the framework of zeolite (Fig. 1). Three pictures indicate the adsorption of $\mathrm{SO}_{2}$ in azoles (imidazole, triazole and tetrazole) modified zeolite ZSM5, respectively.
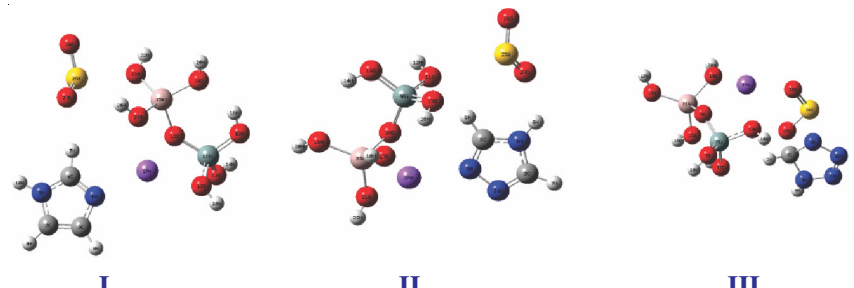

Fig. 1. Optimized structures of $\mathrm{SO}_{2}$ in compounds $\mathbf{I}$, II and III

Three optimized structures (Fig. 1) show that $\mathrm{SO}_{2}$ molecule interacts with zeolite framework and azoles simultaneously, the nitrogen atom in azoles ring points to the extra framework sodium cation, indicating the azole molecules is captured by zeolite at the same time. Therefore, we can conclude that the $\mathrm{SO}_{2}$ capture capability of zeolite is enhanced after the azole molecules are involved.

The energy effect on dissociation process of $\mathrm{SO}_{2}$ in compounds I, II and III have been examined using the following method (as an example with the $\Delta \mathrm{E}$ for compound $\mathbf{I}$ ).

$$
\Delta \mathrm{E}_{\mathrm{d}}=\mathrm{E}_{\mathrm{I}}-\mathrm{E}_{\mathrm{SO}_{2}}-\mathrm{E}_{\mathrm{Na}^{+}}-\mathrm{E}_{\text {azole }}-\mathrm{E}_{\mathrm{ZSM} 5}
$$

The calculated dissociation energies $\left(\Delta \mathrm{E}_{\mathrm{d}}\right)$ of compounds I, II and III, are 47.3, 17.7, $10.7 \mathrm{kcal} \mathrm{mol}^{-1}$ for imidazole, triazole and tetrazole, respectively, indicating that the dissociation is in the order of difficulty I $>$ II $>$ III. Therefore, one may expect the dissociation processes of the adsorption desulfurization in the complexes formed from azoles to have a similar trend.

From Fig. 1, one can clearly find that the major interaction in three compounds happen between the nitrogen atom in azoles ring and zeolite with $\mathrm{SO}_{2}$ molecule. It's necessary to check the charge distribution change of azoles ring nitrogen in monomer and in compound (Table-1). The quantity of nitrogen charge increases from -0.386 to -0.438 when it is involved in compound, which indicates that the nitrogen receives more negative charge to enhance the interaction with $\mathrm{SO}_{2}$ and zeolite, while the charge changes for compounds I and II give converse trend, indicating the nitrogen receives less negative charge to get a weaker interaction with $\mathrm{SO}_{2}$ and zeolite.

\begin{tabular}{ccc}
\multicolumn{4}{c}{ TABLE-1 } \\
MILLIKAN CHARGE DISTRIBUTION OF THE \\
SAME NITROGEN ATOM IN AZOLES RING
\end{tabular}

\section{Conclusion}

Three azole molecules are introduced into ZSM5 zeolite to model a new type of desulfurization adsorbent so-called azoles modified zeolite through theoretical study. The behaviour of sulfur dioxide adsorbed in azoles modified zeolite ZSM5 has been investigated in our work. The results show that the $\mathrm{SO}_{2}$ molecule receives a dual interactions from azoles molecule and zeolite, which indicates the $\mathrm{SO}_{2}$ become more stable in azoles modified zeolite rather than it is in azoles based ionic liquids or in zeolite, the azoles modified zeolite presents a better adsorption capability. When we introduces azole molecules follow the order of imidazole, tridazole and tetrazole, the adsorption capability of azoles modified zeolite is going down through the sequence.

\section{ACKNOWLEDGEMENTS}

This work is financially supported by Anhui Provincial Natural Science Foundation (1308085QB30) and the Talnets Foundation of Hefei University (12RC04). Thanks are also due to Inha University for financial support and the calculation facilities.

\section{REFERENCES}

1. G.B. Han, N.K. Park, J.D. Lee, S.O. Ryu and T.J. Lee, Catal. Today, 111, 205 (2006).

2. K. Tang, X. Hong, Y.H. Zhao and Y.G. Wang, Petrol. Sci. Technol., 29, 779 (2011).

3. J.H. Jacobsen, C. Madsen, T.V.W. Janssens, H.J. Jakobsen and J. Skibsted, Micropor. Mesopor. Mater., 39, 393 (2000).

4. I. Schmidt, C. Madsen and J.H. Jacobsen, Inorg. Chem., 39, 2279 (2000).

5. J.E. Bara, D.E. Camper, D.L. Gin and R.D. Noble, Acc. Chem. Res., 43, 152 (2010).

6. C.M. Wang, G.K. Cui, X.Y. Luo, Y.J. Xu, H.R. Li and S. Dai, J. Am. Chem. Soc., 133, 11916 (2011).

7. H. Zhang and C.K. Kim, Asian J. Chem., 24, 4050 (2012).

8. M.J. Frisch, G.W. Trucks, H.B. Schlegel, G.E. Scuseria, M.A. Robb, J.R. Cheeseman, J.A. Montgomery Jr., T. Vreven, K.N. Kudin, J.C. Burant, J.M. Millam, S.S. Iyengar, J. Tomasi, V. Barone, B. Mennucci, M. Cossi, G. Scalmani, N. Rega, G.A. Petersson, H. Nakatsuji, M. Hada, M. Ehara, K. Toyota, R. Fukuda, J. Hasegawa, M. Ishida, T. Nakajima, Y. Honda, O. Kitao, H. Nakai, M. Klene, X. Li, J.E. Knox, H.P. Hratchian, J.B. Cross, V. Bakken, C. Adamo, J. Jaramillo, R. Gomperts, R.E. Stratmann, O. Yazyev, A.J. Austin, R. Cammi, C. Pomelli, J.W. Ochterski, P.Y. Ayala, K. Morokuma, G.A. Voth, P. Salvador, J.J. Dannenberg, V.G. Zakrzewski, S. Dapprich, A.D. Daniels, M.C. Strain, O. Farkas, D.K. Malick, A.D. Rabuck, K. Raghavachari, J.B. Foresman, J.V. Ortiz, Q. Cui, A.G. Baboul, S. Clifford, J. Cioslowski, B.B. Stefanov, G. Liu, A. Liashenko, P. Piskorz, I. Komaromi, R.L. Martin, D.J. Fox, T. Keith, M.A. Al-Laham, C.Y. Peng, A. Nanayakkara, M. Challacombe, P.M.W. Gill, B. Johnson, W. Chen, M.W. Wong, C. Gonzalez and J.A. Pople, Gaussian03, Revision D.02; Gaussian, Inc.: Pittsburgh, PA (2003). 